\title{
Necrobiotic xanthogranuloma scleritis in a case of granulomatosis with polyangiitis (Wegener's granulomatosis)
}

\author{
This article was published in the following Dove Press journal: \\ International Medical Case Reports Journal \\ 3 October 2017 \\ Number of times this article has been viewed
}

\author{
Narumon Keorochana' \\ Kanaspana Klanarongran ${ }^{2}$ \\ Kantang Satayasoontorn ${ }^{3}$ \\ Sumapa Chaiamnuay ${ }^{4}$ \\ 'Department of Ophthalmology, \\ Ocular Inflammatory and \\ Uveitis Division, ${ }^{2}$ Department of \\ Ophthalmology, External Disease \\ and Cornea Division, ${ }^{3}$ Department \\ of Anatomic Pathology, ${ }^{4}$ Department \\ of Medicine, Rheumatology \\ Division, Phramongkutklao Hospital, \\ Phramongkutklao College of Medicine, \\ Bangkok, Thailand
}

\begin{abstract}
The purpose of this study was to describe a case of necrobiotic xanthogranuloma scleritis in a 53-year-old male with unilateral progressive visual loss, scleritis, prolonged fever, and multiple mononeuropathy. Scleral biopsy showed necrosis with small abscess, and the pathological tissues revealed submucosal infiltration of mononucleated foamy histiocytes (xanthoma cells), hemosiderin-laden macrophages, neutrophils, lymphocytes, plasma cells, and erythrocytes without Touton giant cells or cholesterol clefts. Serum protein electrophoresis showed polyclonal gammopathy. All infectious investigations were negative. Afterward, this patient was diagnosed with granulomatosis with polyangiitis based on granuloma found in scleral tissue, vasculitis seen in sural nerve biopsy and positive serologies (C-ANCA and anti-PR3 antibody). He was treated with high-dose corticosteroid and later with intravenous cyclophosphamide monthly. $\mathrm{He}$ responded well to treatment, both eye and systemic conditions. Necrobiotic xanthogranuloma scleritis could be an early presentation of granulomatosis with polyangiitis.
\end{abstract}

Keywords: scleritis, uveitis, ocular inflammation, pathology, autoimmune, xanthoma cells, GCA

\section{Case report}

In 2016, a 53-year-old man for the first time was admitted in Phramongkutklao Hospital. He had suffered from progressive visual loss and redness for 2 months in the left eye without any photophobia, ocular pain, or discharge. His right eye was not affected. The visual acuity was $20 / 20$ in the right eye and hand movement in the left eye. The examination of the left eye showed generalized ciliary injection with whitish scleral nodule at inferotemporal area. Anterior segment examination revealed anterior chamber cell $3+$, seclusio pupillae. Fundus examination showed vitreous haze with unclear retinal details. Intraocular pressure was 18 in both the eyes. The right eye was normal when examined.

Ocular ultrasonography showed hypohyperechogenicity, membrane-like lesion in intravitreous cavity without retinal detachment, fluid collection, or any mass. Nodular scleritis and chronic panuveitis in the left eye was the initial diagnosis.

Scleral exploration, phacoemulsification with intraocular lens implantation, and diagnostic vitrectomy left eye were performed. In intraoperative, we found scleral necrosis with small abscess (Figure 1A and B) at inferotemporal area. The fundus showed dense yellowish turbid vitritis (Figure 2), retinal and perivascular infiltration, retinal edema, and shallow subretinal fluid at inferior retina. A vitreous sample was sent to the laboratory to perform polymerase chain reaction (PCR) for tuberculosis,
Correspondence: Narumon Keorochana Department of Ophthalmology, External Disease and Cornea Division, Phramongkutklao Hospital, 315 Ratchvidhi Road, Thung Phaya Thai, Ratchathewi, Bangkok 10400, Thailand Tel +6627639300 Email narumon_keo@hotmail.com 


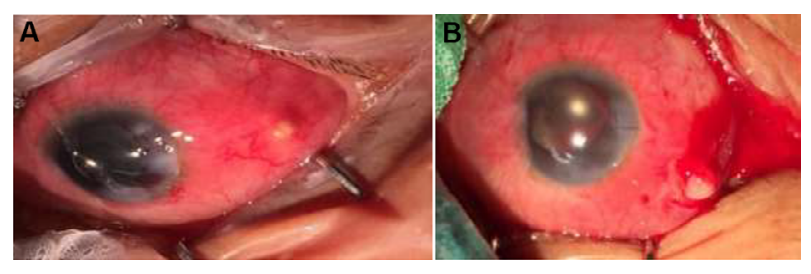

Figure I (A) and (B) show generalized diffuse scleritis with scleral abscess inferotemporal area.

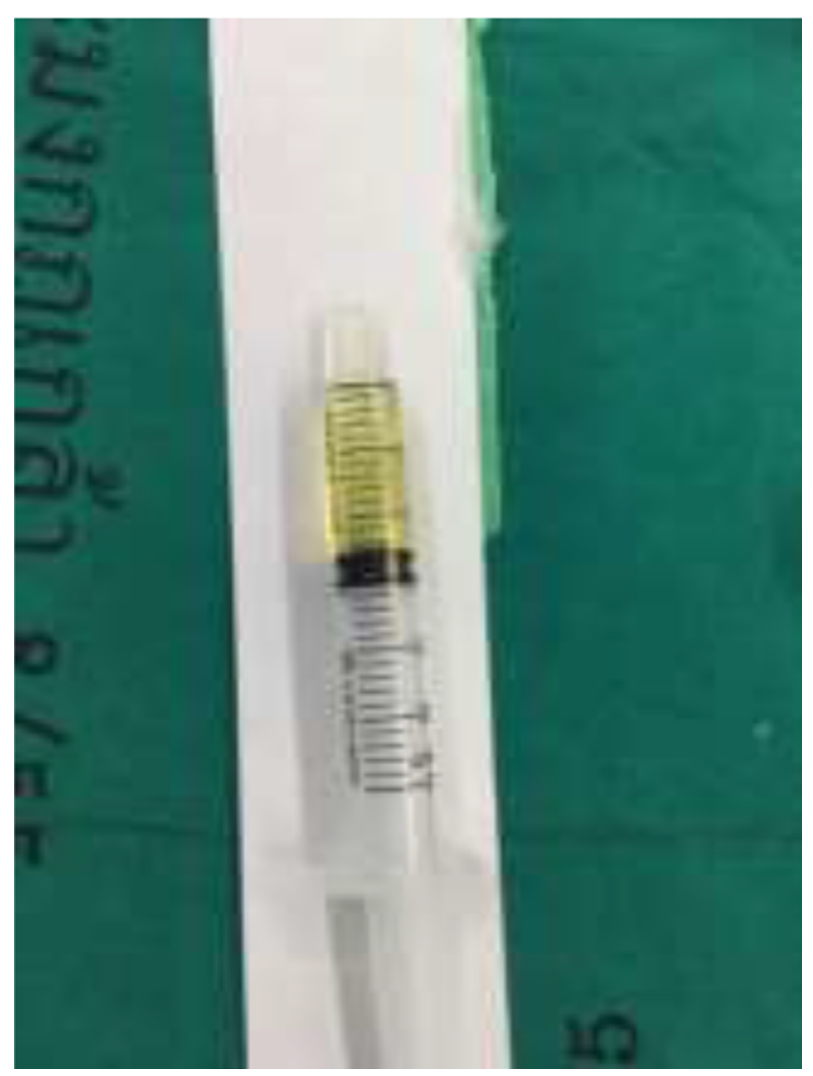

Figure 2 Turbid yellowish vitreous fluid from diagnostic vitrectomy.

herpesvirus family, gram stain, potassium hydroxide $(\mathrm{KOH})$, culture for bacteria and fungus, and cytology for malignancy.

The left eye was treated as infectious scleritis and endophthalmitis by using intravenous cefazolin and amikacin for 2 weeks followed by oral augmentin, topical cefazolin, and amikacin which were later changed to vancomycin and ceftazidime, 3 times of sclera debridement, and intravitreous vancomycin and ceftazidime injection. After the treatment for 2 weeks, the findings on his left eye showed no improvement.

The investigations included scleral and vitreous gram stain, $\mathrm{KOH}$, culture for bacteria, fungus, mycobacteria, PCR for herpes 7 types, and tuberculosis which were all negative. The pathology of scleral biopsy presented necrobiotic xanthogranulomatous inflammation of sclera with severe acute and chronic inflammation and mycobacteria and fungus were also negative. He was diagnosed with necrobiotic xanthogranulomatous scleritis with panuveitis in the left eye. Then, topical $1 \%$ prednisolone acetate eye drop 4 times a day and oral prednisolone $1 \mathrm{mg} / \mathrm{kg} /$ day were prescribed. The clinical injection and sclera necrosis, was much improved that included the decrease of anterior chamber cells from $3+$ to $1+$ after the administration of steroids; however, the visual acuity was still hand motion. After that, steroids were slowly tapered.

After 5 months, the patient was admitted to internal medicine service for prolonged fever. He had low-grade fever without chills for 6 weeks. No source of infection was identified after thorough evaluation including blood culture, urine culture, bone marrow aspiration, echocardiogram, and chest film. He was treated with ceftriaxone and doxycycline for 7 days with no improvement and was later switched to meropenem for 7 days without resolution of fever. During this admission, he developed bilateral foot drop and numbness in both hands.

This time of admission, besides fever, foot drop and numbness, he complained of transient visual loss duration of 1 minute 5-6 times a day in his right eye. Physical examination found high blood pressure $150 / 100 \mathrm{mmHg}$ and body temperature of $39^{\circ} \mathrm{C}$. The visual acuity was $20 / 70$ in the right eye and light projection in the left eye. The right eye presented dot and blot hemorrhage at posterior pole of fundus. The left eye was not injected and showed quiet anterior chamber with occlusio pupillae. He had no rash or cervical lymphadenopathy. Heart, lung, and abdominal examinations were normal. Neurological examination confirmed weakness of ankle flexion, bilaterally and numbness in both hands. It consisted with pathology in common peroneal nerve and median nerve, respectively which were consistent with multiple mononeuropathy.

Initial work-up found hemoglobin of $8.3 \mathrm{mg} / \mathrm{dL}$, white blood cell count of 11,400 cell $/ \mathrm{mL}$, platelet of $107,000 / \mathrm{mL}$, erythrocyte sedimentation rate (ESR) $31 \mathrm{~mm} / \mathrm{h}$, creatinine $1.0 \mathrm{mg} / \mathrm{dL}$, blood urea nitrogen $1.3 \mathrm{mg} / \mathrm{dL}$, aspartate aminotransferase $17 \mathrm{IU} / \mathrm{L}$, alanine aminotransferase $20 \mathrm{IU} / \mathrm{L}$, total bilirubin $0.5 \mathrm{mg} / \mathrm{dL}$, direct bilirubin $0.2 \mathrm{mg} / \mathrm{dL}, T G$ $78 \mathrm{mg} / \mathrm{dL}$, cholesterol $194 \mathrm{mg} / \mathrm{dL}$, high-density lipoprotein $86 \mathrm{mg} / \mathrm{dl}$, and low-density lipoproteins $114 \mathrm{mg} / \mathrm{dL}$. Peripheral blood smear revealed normochromic microcytic red blood cells, normal morphology of WBC, and platelet. Both direct and indirect Coombs tests were negative. Urine analyses found no proteinuria, red blood cell 3-5 cell/HPF, white blood cell 0-1 cell/HPF, and no red blood cast. Serum protein electrophoresis showed polyclonal gammopathy with albumin $36.5 \%$, alpha1 $8.2 \%$, alpha2 $14.9 \%$, beta1 $6.1 \%$, beta2 $5.2 \%$, gamma $29.1 \%$. 
Infectious work-up were negative including HIV, hepatitis B virus, hepatitis C virus, Quantiferon TB gold test, treponema pallidum hemagglutination, and venereal disease research laboratory test.

Immunologic studies found positive antinuclear antibody 1:80 speckle pattern. Anti-ds-DNA and antiextractable nuclear antibody was negative. Anti-neutrophilic cytoplasmic antibody (ANCA) found cytoplasmic pattern and later confirmed that anti-proteinase 3 (PR3) positive $3+$, IgG4 was $4.60 \mathrm{~g} / \mathrm{L}$. Chest X-ray was normal. Nerve conduction study and electromyography found asymmetrical axonal sensory motor polyneuropathy. Left sural nerve biopsy confirmed mild medium-sized vasculitis.

This patient was diagnosed with granulomatosis with polyangiitis based on granuloma found in scleral tissue, vasculitis seen in sural nerve biopsy and serologies (C-ANCA and anti-PR3 antibody).

This patient was treated with high-dose dexamethasone and later switched to prednisolone $(1 \mathrm{mg} / \mathrm{kg} /$ day $)$ and intravenous cyclophosphamide monthly as well as antihypertensive drugs. He responded well to treatment, ankles flexion improved and numbness of both hands was reduced. Regarding the transient visual loss, the computed tomography angiography was done and no filling defect was reported. The amaurosis fugax was diagnosed and suspected from vasculitis. He did not develop recurrent transient visual loss. At the final visit, the visual acuity was 20/20 in the right eye and no light perception in the left eye. Both eyes were not injected and quite anterior chamber. The left eye presented early phthisis bulbi.
This case report was approved by the Institutional Review Board, Royal Thai Army Medical Department. Written informed consent was obtained from the patient to have the case details and for any accompanying images published.

\section{Pathology}

Multiple scleral biopsies were performed, and the findings revealed erosive scleral mucosa with submucosal infiltration by sheets of mononucleated foamy histiocytes (xanthoma cells), accompanied by variable degree of fibrosis with necrobiosis of collagen (Figures 3 and 4). Variable numbers of dispersed hemosiderin-laden macrophages, neutrophils,

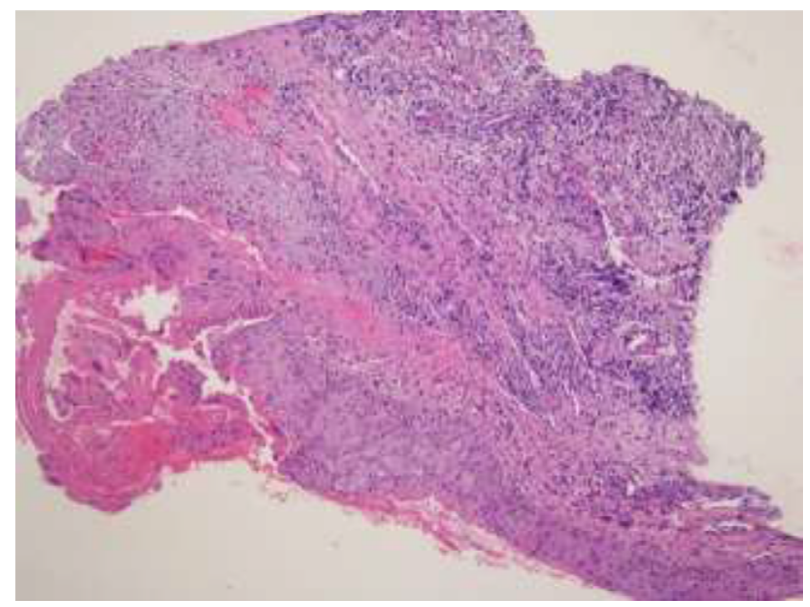

Figure 3 A scleral tissue biopsy showing mucosal erosion and submucosal fibrosis with necrobiosis of collagen and sheets of mononucleated foamy histiocytes (xanthoma cells), infiltrating the submucosal fibrous tissue, accompanied by variable numbers of dispersed lymphocytes and plasma cells (hematoxylin-eosin; original magnification: $\times 40$ ).

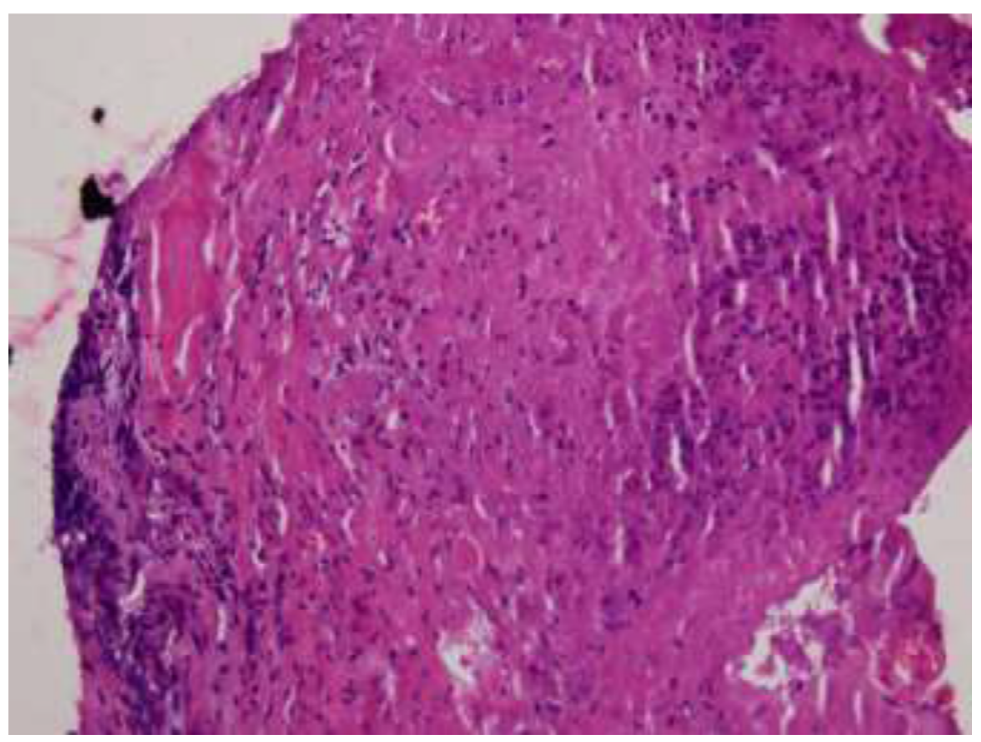

Figure 4 Another scleral tissue biopsy predominantly containing fibrosis with necrobiosis of collagen and scattered necrotic cellular debris of inflammatory cells (hematoxylineosin; original magnification: $\times 200)$. 


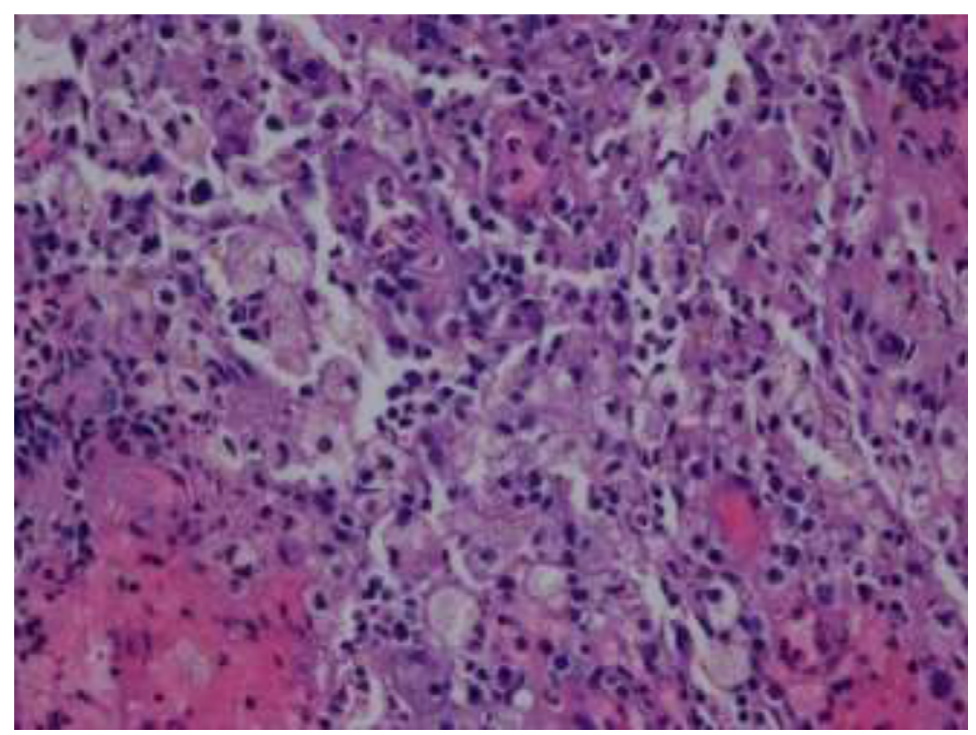

Figure 5 Sheets of xanthoma cells and scattered hemosiderin- laden macrophages, neutrophils, lymphocytes, plasma cells, and erythrocytes. The xanthoma cells have small, round nuclei and abundant clear or vacuolated cytoplasm (hematoxylin-eosin; original magnification: $\times 400$ ).

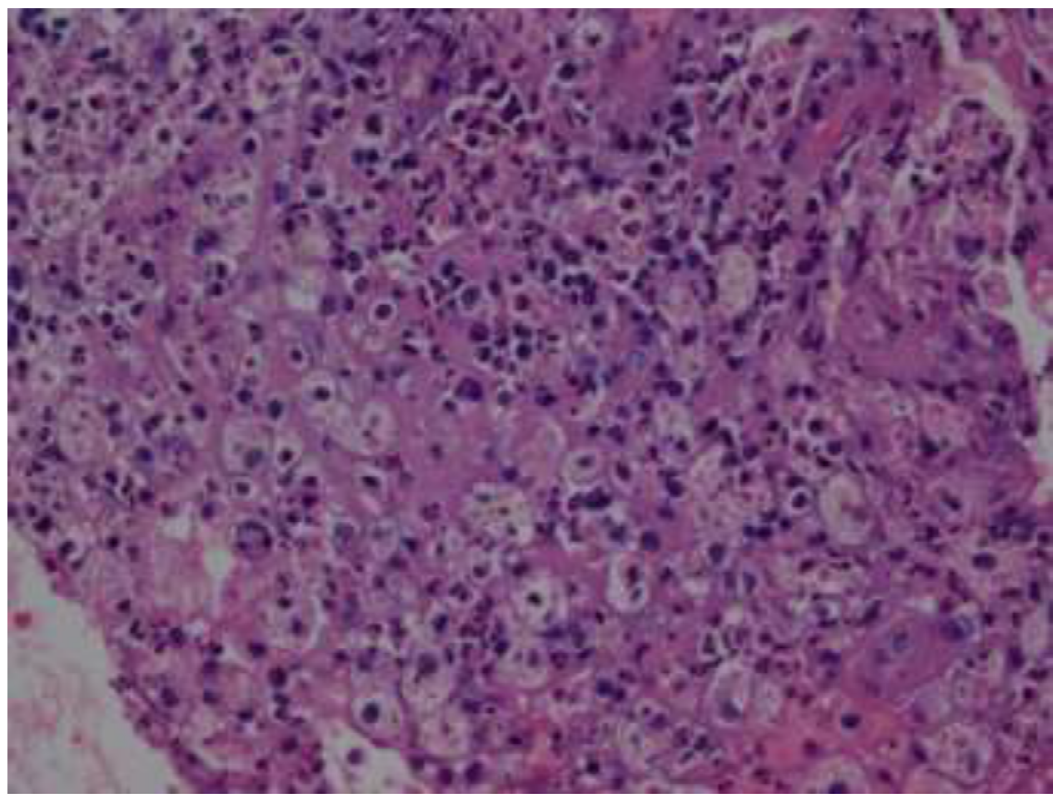

Figure 6 Some of infiltrating histiocytes show hemophagocytic activity characterized by intracytoplasmic nuclear debris (hematoxylin-eosin; original magnification: $\times 400$ ).

lymphocytes, plasma cells, and erythrocytes without Touton giant cells, or cholesterol clefts were scattered among these xanthoma cells. These infiltrating xanthoma cells often have small, round nuclei, and abundant clear or vacuolated cytoplasm (Figure 5). Some of these histiocytes show hemophagocytic activity (Figure 6). Despite the absence of Touton giant cells and cholesterol clefts, the findings previously confirmed were favorable of necrobiotic xanthogranulomatous inflammation of the sclera. ${ }^{1}$ Left sural nerve biopsy confirmed small- and medium-sized vasculitis by lymphocytic and neutrophilic infiltrate in wall of subcutaneous vessels (Figure 7).

\section{Discussion}

Scleritis is a destructive ocular inflammation mostly associated immune-mediated cause with or without systemic collagen vascular disease. It is very important in differentiating between infectious and noninfectious scleritis by using predisposing factors, clinical sign, symptoms, and diagnostic tools. ${ }^{1}$ The two diseases most often associated 


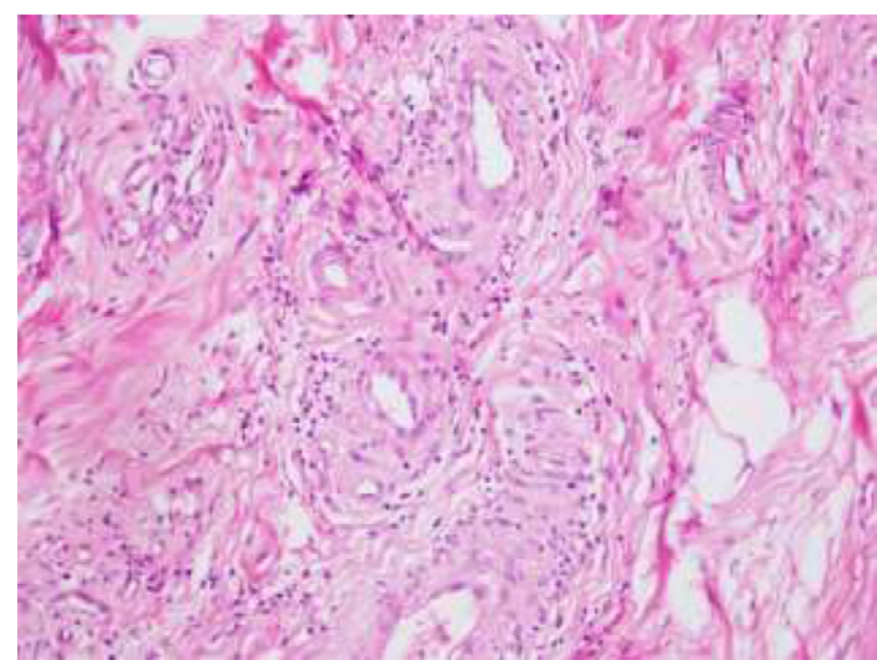

Figure 7 Small- and medium-sized vasculitis characterized by lymphocytic and neutrophilic infiltrate in wall of subcutaneous vessels obtained from sural nerve biopsy (hematoxylin-eosin; original magnification: $\times 200$ ).

are granulomatosis with polyangiitis and rheumatoid arthritis. ${ }^{2}$ The others were inflammatory bowel disease, relapsing polychondritis, systemic lupus erythematosus, polyarteritis nodosa, giant cell arteritis, Behçet's disease, seronegative spondyloarthropathies, sarcoidosis, systemic sclerosis, IgA nephropathy, and gout. ${ }^{3,4}$ Watson et $a l^{5}$ classified the scleritis disorder into anterior and posterior types based upon the anatomical distribution of the disease. Anterior scleritis is further subdivided into diffuse, nodular, necrotizing with and without inflammation by ocular examination. However, scleral biopsy could give the clinician more useful information for the correct diagnosis such as in this case. Scleral biopsy showed necrobiotic xanthogranulomatous inflammation.

Xanthogranulomas are granulomas, in which histiocytes are filed with a lipid yellow material, ${ }^{6}$ both clinically for superficial lesions and on gross specimens examination of resected specimens. Necrobiotic xanthogranuloma was first described by Kossard and Winkelmann ${ }^{7}$ in 1980. They found 8 patients who had multiple xanthomatous plaques and subcutaneous nodules in periorbital area, flexures, and trunk. All patients had dysproteinemia, mostly a monoclonal IgG paraprotein. Laboratory abnormalities commonly included monoclonal gammopathy, increased erythrocyte sedimentation rate, and leukopenia. After that, in 1991 Rose et al reported three patients presented with proptosis and subcutaneous nodule at eyelid. Histopathological finding revealed foamy cytoplasm, giant cell, and lymphocytic infiltration. These were characteristics of xanthogranulomatous inflammation, which represent the necrobiotic type.

Since then, many literatures ${ }^{9-11}$ have described this problem and classified it into 4 following subtypes from histopathological findings, laterality, systemic associations, and prognosis: 1) adult onset xanthogranuloma which is often associated with hematological disorder, 2) adult onset asthma and periocular xanthogranuloma which is rare and associated with asthma, 3) necrobiotic xanthogranuloma which is often associated with paraproteinemia, multiple myeloma or lymphoproliferative disorders, and 4) Erdheim-Chester disease which is associated with vital organ involvement resulting in death. One common thing in all subtypes is xanthoma cells which are mononucleated foamy histiocytes with or without Touton giant cells. In addition, the earlier literatures reported disorder only in orbit and eyelid.

Later on, the literatures have begun to report that a group of patients with necrobiotic xanthogranuloma had decreased vision, proptosis, scleritis, and uveitis. Some patients had no systemic causes, ${ }^{12,13}$ while some patients had paraproteinemia ${ }^{14}$ and leukemia. ${ }^{15}$ Ugurlu et al reported a large series of necrobiotic xanthogranuloma with ocular and systemic involvement. ${ }^{16}$ They found that $81 \%$ had lesions of the ocular adnexa, $90 \%$ were bilateral, that included eye lids, skin lesions, proptosis, abnormal epibulbar tissue, episcleritis, keratitis, blepharoptosis, and restricted ocular motility. Approximately $23 \%$ were not related with any systemic disease.

One interesting case report by Alkatan and Al-Abdullah, ${ }^{17}$ a case of necrobiotic xanthogranuloma with bilateral scleritis and orbital involvement was first diagnosed as Wegener's granulomatosis. Necrobiotic xanthogranuloma was definitely diagnosed after clinical and histopathological reviews later. This means both diseases have something similar that includes clinical or histopathological findings.

Granulomatosis with polyangiitis (GPA) or Wegener's granulomatosis has classic triads including vasculitis of respiratory tract, glomerulonephritis, and systemic or necrotizing 
vasculitis. Eye involvement is found in $15 \%$ of patients at the first manifestation and in up to $50 \%$ of patients during active disease. ${ }^{18,19}$ The most common eye problem is orbital involvement (45\%-70\%), followed by scleritis (40\%), retinal vasculitis $(20 \%)$, uveitis $(10 \%)$, and uncommon ischemic optic neuropathy. ${ }^{20,21}$ The diagnosis requires tissue biopsy, chest $\mathrm{x}$-ray, urinalysis unstable angina, ESR, C-reactive protein test and ANCA. A positive biopsy is very useful to confirm the diagnosis of GPA. The histological features of GPA are granulomatous foci, tissue necrosis, plasma cells, and infiltration with neutrophils and eosinophils, small vessels vasculitis, and microabscess. ${ }^{22-25}$

To the best of our knowledge, this case report first identified the relationship between necrobiotic xanthogranuloma scleritis and granulomatosis with polyangiitis. Early diagnosis of GPA is very important as it enables the appropriate treatments such as immunosuppressive therapy for reducing the risk of progression of the disease early and the involvement of other vital organs which could possibly deteriorate the prognosis dramatically.

\section{Conclusion}

Necrobiotic xanthogranuloma scleritis is an uncommon finding; however, it could be an early presentation of granulomatosis with polyangiitis. The multidisciplinary team is useful and important for taking care of these patients.

\section{Disclosure}

The authors report no conflicts of interest in this work.

\section{References}

1. Murthy SI, Reddy JC, Sharma S, Sangwa VS. Infectious scleritis. Curr Ophthamol Rep. 2015;3:147-157.

2. Smith JR, Mackensen F, Rosenbaum JT. Therapy insight: scleritis and its relationship to systemic autoimmune disease. Nat Clin Pract Rheumatol. 2007;3(4):219-226.

3. Tappeiner C, Walscheid K, Heiligenhaus A. Diagnosis and treatment of episcleritis and scleritis. Ophthalmology. 2016;113(9):797-810.

4. Dubord PJ, Chalmers A. Scleritis and episcleritis: diagnosis and management. In: Focal Points: Clinical Modules for Ophthalmologist. San Francisco: American Academy of Ophthalmology; 1995: module 9.

5. Watson PG, Hayreh SS, Awdry PN. Episcleritis and scleritis. $\mathrm{Br} \mathrm{J}$ Ophthalmol. 1968;52(3):278-279.
6. Cozzutto C, Carbone A. The xanthogranulomatous process. Xanthogranulomatous inflammation. Pathol. Res. Pract. 183(4):395-402.

7. Kossard S, Winkelmann RK. Necrobiotic xanthogranuloma with paraproteinemia. J Am Acad Dermatol. 1980;3(3):257-270.

8. Rose GE, Patel BC, Garner A, Wright JE. Orbital xanthogranuloma in adults. Br J Ophthamol. 1991;75:680-684.

9. Sivak-Callcott JA, Rootman J, Rasmussen SL, et al. Adult xanthogranulomatous disease of the orbit and ocular adnexa: new immunohistochemical findings and clinical review. Br J Ophthalmol. 2006;90(5):602-608.

10. Guo J, Wang J. Adult orbital xanthogranulomatous disease: review of the literature. Arch Pathol Lab Med. 2009;133(12):1994-1997.

11. Rayner SA, Duncombe AS, Keefe M, Theaker J, Manners RM. Necrobiotic xanthogranuloma occurring in an eyelid scar. Orbit. 2008;27(3):191-194.

12. Peyman A, Walsh N, Green P, Dorey MW, Seamone C, Pasternak S. Necrobiotic xanthogranuloma associated with necrotizing scleritis. $\mathrm{Am}$ J Dermatopathol. 2012;34(6):644-647.

13. Lavric A, Agrawal R, Pavesio C. A case of necrobiotic xanthogranuloma presenting as bilateral posterior scleritis. J Immunol Inflamm. 2016:1-3.

14. Wilhelmus KR, Yen MT, Rice L, Font RL. Necrobiotic xanthogranuloma with posterior scleritis. Arch Ophthalmol. 2006;124(5).

15. Mohsenin A, Sinard J, Huang JJ. Necrobiotic xanthogranuloma and chronic lymphocytic leukemia of the conjunctiva masquerading as scleritis and uveitis. Clin Ophthalmol. 2012;6:2045-2047.

16. Ugurlu S, Bartley GB, Gibson LE. Necrobiotic xanthogranuloma: longterm outcome of ocular and systemic involvement. Am J Ophthalmol. 2000;129(5):651-657.

17. Alkatan HM, Al-Abdullah AEA. Orbital necrobiotic xanthogranuloma: a case report. Int J Pathol Clin Res. 2015;1:2.

18. Hoffman GS, Kerr GS, Leavitt RY. Wegener's granulomatosis: an analysis of 158 patients. Ann Intern Med.1992;116(6):488-498.

19. Ismailova DS, Novikov PI, Grusha YO, Abramova YV, Bulanov NM, Makarov EA. The frequency of ophthalmologic manifestations of granulomatosis with polyangiitis (Wegener's) and their relationship to systemic diseases. Ter Arkh. 2017;89(5):69-73.

20. Ursea R, Nussenblatt RB, Ronald RB. Wegener's granulomatosis, a patient education monograph prepared for the American Uveitis Society. February 2003.

21. Pakrou N, Selva D, Leibovitch I. Wegener's granulomatosis: ophthalmic manifestations and management. Semin Arthritis Rheum. 2006;35(5):284-292.

22. Ahmed M, Niffenegger JH, Jakobiec FA, et al. Diagnosis of limited ophthalmic Wegener granulomatosis: distinctive pathologic features with ANCA test confirmation. Int Ophthalmol. 2008;28:35-46.

23. Isa H, Lightman S, Luthert PJ, Rose GE, Verity DH, Taylor SR. Histopathological features predictive of a clinical diagnosis of ophthalmic granulomatosis with polyangiitis (GPA). Int J Clin Exp Pathol. 2012;5(7):684-689.

24. Muller K, Lin JH. Orbital granulomatosis with polyangiitis (Wegener granulomatosis): clinical and pathologic findings. Arch Pathol Lab Med. 2014;138(8):1110-1114.

25. Kalina PH, Lie JT, Campbell RJ, Garrity JA. Diagnostic value and limitations of orbital biopsy in Wegener's granulomatosis. Ophthalmology. 1992;99(1):120-124.
International Medical Case Reports Journal

\section{Publish your work in this journal}

The International Medical Case Reports Journal is an international, peer-reviewed open-access journal publishing original case reports from all medical specialties. Previously unpublished medical posters are also accepted relating to any area of clinical or preclinical science. Submissions should not normally exceed 2,000 words or

\section{Dovepress}

4 published pages including figures, diagrams and references. The manuscript management system is completely online and includes a very quick and fair peer-review system, which is all easy to use. Visit $\mathrm{http}: / /$ www.dovepress.com/testimonials.php to read real quotes from published authors. 